\title{
Effect of Nanosilica Particle Size on the Water Permeability, Abrasion Resistance, Drying Shrinkage, and Repair Work Properties of Cement Mortar Containing Nano-SiO
}

\author{
Sattawat Haruehansapong, Tawich Pulngern, and Somchai Chucheepsakul \\ Department of Civil Engineering, Faculty of Engineering, King Mongkut's University of Technology Thonburi, Bangkok 10140, Thailand \\ Correspondence should be addressed to Tawich Pulngern; tawich.pul@kmutt.ac.th
}

Received 7 December 2016; Revised 7 March 2017; Accepted 20 March 2017; Published 2 April 2017

Academic Editor: Patrice Berthod

Copyright (c) 2017 Sattawat Haruehansapong et al. This is an open access article distributed under the Creative Commons Attribution License, which permits unrestricted use, distribution, and reproduction in any medium, provided the original work is properly cited.

\begin{abstract}
This work presents the effect of nanosilica particle sizes on durability properties and repair work properties of cement mortar containing nanosilica (NS). Three different NS particle sizes of 12, 20, and $40 \mathrm{~nm}$ were used and compared with those of cement mortar without NS and cement mortar with silica fume (SF). Interesting results were obtained in which the particle size of NS affected directly the abrasion resistance and water permeability. NS with particle size of $40 \mathrm{~nm}$ is the optimum size and gave the highest abrasion resistance and water permeability. For repair work properties, cement mortars containing NS (12 and $20 \mathrm{~nm}$ ) and SF experienced higher drying shrinkage than that of cement mortar without NS and then presented cracking behavior and debonding between the cement mortars and concrete substrate. Cement mortar containing $40 \mathrm{~nm}$ of NS gave the lowest drying shrinkage, the lowest crack number, and the highest adhesive strength. These results indicate that the particle size of NS affected not only the durability properties but also the repair work properties of cement mortar.
\end{abstract}

\section{Introduction}

In recent years, the repair material used for the maintenance of concrete structures has become a significant part of the total cost of construction [1]. Different repair methods and materials are currently being applied to overcome the damage in deteriorated structures. Concrete repair quality is generally specified in terms of durability, in addition to workability and strength. Most of the durability-related problems of repair systems are due to the lack of compatibility with the concrete substrate. The durability of concrete repair depends on many factors: a combination of physical, chemical, and mechanical processes [2-4]. Moreover, failure of a concrete repair material is more likely to occur due to incompatibility between the repair material and the concrete substrate, leading to cracking and debonding [5]. Therefore, some researchers [611] suggested that an important factor in successful repair work of concrete structures is to achieve sufficient bonding between the repair material and the concrete substrate [611] while another critical factor affecting the successful repair work of structures is the selection of repair material [12]. As mentioned previously, the published researches concluded that repair materials used for the maintenance of concrete structure are very important. Almost published researches focused on cracking and debonding behaviors of repair materials. However, information about durability and repair work properties of these repair materials is still rarely found.

At present, it has been observed that the addition of nanomaterials to cementitious composites can enhance their mechanical and durability properties [13-16]. Nanosilica (NS) is one of the most desirable types of nanomaterials for incorporation in cementitious composites, and NS has been widely investigated in various studies. These works [13-16] also reported that admixing small amounts of NS (1-3\%) could modify the properties of cementitious composites, including strength, microstructure, and durability. Qing et al. [17] applied NS with particle size of $15 \mathrm{~nm}$ for cement paste and found that NS could improve the bond strength of the paste-aggregate interface. Li et al. [18] suggested that NS with particle size of $10 \mathrm{~nm}$ enhanced significantly 
the abrasion resistance of pavement concrete while Shih et al. [19] reported that NS with particle size of $20 \mathrm{~nm}$ could fill up the pores in the cementitious composites and also exhibited the characteristics of pozzolanic activity. Later, Ji [20] also found that NS with particle size of $15 \mathrm{~nm}$ significantly improved the microstructure, compressive strength, and permeability of cement mortar. Some researchers [21$24]$ also suggested that the addition of NS in cement mortar not only increases the compressive strength, which is mainly attributed to a reduction in total porosity, but also results in a finer pore structure and then reduces overall permeability of hardened concrete. Zhang and Li [21] studied the pore structure of concrete containing NS $(10 \mathrm{~nm})$ and found that the addition of NS could refine the pore structure of concrete since NS acts as a filler to enhance the density of concrete, which causes the reduction of total porosity. Moreover, SEM test results also indicated that the microstructure of cement mortar containing NS gave a denser and more compact texture than that of the mortar without NS $[22,24]$.

As mentioned previously, the addition of NS particle to cement mortar and concrete results in higher mechanical properties, lower setting time and water permeability, and higher resistance to chemical attacks. Therefore, the application of cement mortar containing NS as a repair material for the maintenance of concrete structures is very interesting. The cement mortar with the right composition of NS can definitely improve both the compressive strength and the durability properties of the repair material. Moreover, almost published articles related to durability properties of cement mortar and concrete focused on the addition of only single-sized NS particles. The effect of nanosilica particle size was rarely discussed and the question still remained. Only our previous work [22] suggested that the particle size of nanosilica affected significantly the compressive strength and microstructure of cement mortar. For cement mortar containing $9 \%$ of NS content and water per binder ratio of 0.65 , the compressive strengths of cement mortars with NS particle sizes of 12,20 , and $40 \mathrm{~nm}$ were higher than that of cement mortar without nanosilica about 1.32, 1.67, and 1.74 times, respectively.

Therefore, the main objective of this study is to investigate the effect of NS particle sizes on the durability properties and repair work properties of cement mortar containing NS compared with those of cement mortar containing silica fume (SF) and control mortar without NS. We believe that our results not only give a comprehensive understanding of the effect of particle size of NS on durability and repair work properties for cement mortar, but also would interest engineers and scientists who want to use cement mortar containing NS as a repair material for structural members.

\section{Experimental Program}

2.1. Materials. The cement used was ordinary Portland cement (OPC) type I with an average particle size of $15,000 \mathrm{~nm}$ while SF was dry-densified (D) with an average particle size of $100 \mathrm{~nm}(0.1 \mu \mathrm{m})$ with a main chemical composition of $88.3 \% \mathrm{SiO}_{2}$. For nanosilica (NS), it consisted of $99.8 \%$
$\mathrm{SiO}_{2}$. Since the effect of NS particle size is the main focus of this study, three different particle sizes of NS, with average diameters of $12 \mathrm{~nm}$ (AEROSIL 200), $20 \mathrm{~nm}$ (AEROSIL 90), and $40 \mathrm{~nm}$ (AEROSIL OX50), were used. These NS products, according to the manufacturer's data, have specific surface areas of 200,90 , and $50 \mathrm{~m}^{2} / \mathrm{g}$, respectively. The silica nanoparticles used in this paper were bought from Evonik Industries, Germany. The chemical compositions of OPC, SF, and NS materials are given in Table 1. Standard natural river sand with specific gravity of $2.50 \mathrm{~g} / \mathrm{cm}^{3}$ was used. In order to achieve the desired fluidity and better dispersion of nanoparticles, a polycarboxylate ether base superplasticizer (ADVA ${ }^{\circledR}$ Cast 207; Grace, Columbia, MD, USA) was incorporated into all mixes. The previous work [25] also suggested that a superplasticizer (SP) can be used to reduce the particle agglomeration mechanisms of cement mortar containing nanosilica.

\subsection{Methodology}

2.2.1. Sample Preparation. For all mix proportions, it is required to achieve $105-115 \%$ flow capacity, according to ASTM C1437 [27]. By the trial test of control cement mortar without NS, water per binder ratio (W/B) of 0.65 was obtained. Then, all cement mortars with NS were prepared by fixing W/B to be 0.65 and sand/binder ratio to 2.75. Moreover, $\mathrm{SP}$ was also added for all mixtures to achieve the required flow capacity. River sand was graded in accordance with ASTM C778 [28]. The mortar samples were classified into 5 groups. The control cement mortar (without NS) was defined as OPC while cement mortars containing SF and three different particle sizes of NS were defined as SF $(100 \mathrm{~nm})$, NS12, NS20, and NS40, respectively. The amount of SF and NS replacement content for all mortar samples was fixed at $9 \%$ by weight of cement, which was the optimum replacement content in cement mortar obtained from our previous work [22]. Details of mixture proportions and flow capacity of the cement mortars containing NS are given in Table 2.

2.2.2. Mixing Procedures. The rotary mixer is used for cement mortars mixing. Since the nanoparticles are not easy to disperse uniformly due to their high specific surface areas, special mixing procedures were used as follows:

(1) The nanosilica particles were firstly mixed with water and superplasticizer at high speed $(285 \mathrm{rpm})$ for 1 minute.

(2) The cement and SF (if applicable) were added to the rotary mixer, and the mixer was allowed to run at medium speed $(140 \mathrm{rpm})$ for another 1 minute. Then, river sand was added within 30 seconds.

(3) The mixture was allowed to rest for 90 seconds and then mixing was continued for 1 minute at high speed.

2.2.3. Abrasion Resistance. The specimens for abrasion resistance test were prepared as a cylindrical specimen with a diameter of $100 \mathrm{~mm}$ and thickness of $30 \mathrm{~mm}$. Then, cement mortars were cured for 28 days and then used to determine 
TABLE 1: Chemical composition of ordinary Portland cement, silica fume, and nanosilica.

\begin{tabular}{|c|c|c|c|c|c|}
\hline \multirow{2}{*}{ Item } & \multicolumn{5}{|c|}{ Chemical composition (\%) } \\
\hline & OPC & Silica fume & AEROSIL 200 & AEROSIL 90 & AEROSIL OX 50 \\
\hline $\mathrm{SiO}_{2}$ & 22 & 88.3 & 99.8 & 99.8 & 99.8 \\
\hline $\mathrm{Al}_{2} \mathrm{O}_{3}$ & 6.6 & 1.17 & - & - & - \\
\hline $\mathrm{Fe}_{2} \mathrm{O}_{3}$ & 2.8 & 4.76 & - & - & - \\
\hline $\mathrm{CaO}$ & 60.1 & 0.48 & - & - & - \\
\hline $\mathrm{MgO}$ & 3.3 & 2.14 & - & - & - \\
\hline $\mathrm{SO}_{3}$ & 2.1 & 1.05 & - & - & - \\
\hline LOI & 2.6 & 2.1 & 0.2 & 0.2 & 0.2 \\
\hline Surface area $\left(\mathrm{m}^{2} / \mathrm{g}\right)$ & 0.38 & 20 & 200 & 90 & 50 \\
\hline Mean particle size (nm) & 15,000 & 100 & 12 & 20 & 40 \\
\hline
\end{tabular}

OPC: ordinary Portland cement.

AEROSIL 200: nanosilica with particle size of $12 \mathrm{~nm}$.

AEROSIL 90: nanosilica with particle size of $20 \mathrm{~nm}$.

AEROSIL OX 50: nanosilica with particle size of $40 \mathrm{~nm}$.

LOI: loss on ignition.

TABLE 2: Mixtures proportions for the cement mortars.

\begin{tabular}{|c|c|c|c|c|c|c|c|}
\hline \multirow[b]{2}{*}{ Sample } & \multicolumn{6}{|c|}{ Mixture proportions (g) } & \multirow{2}{*}{$\begin{array}{c}\text { Flow } \\
\text { capacity }\end{array}$} \\
\hline & $\begin{array}{c}\text { Cement } \\
(\mathrm{g})\end{array}$ & $\begin{array}{l}\text { Water } \\
(\mathrm{mL})\end{array}$ & $\begin{array}{l}\text { Sand } \\
(\mathrm{g})\end{array}$ & $\begin{array}{c}\text { Nanosilica } \\
(\mathrm{g})\end{array}$ & $\begin{array}{c}\text { Silica fume } \\
(\mathrm{g})\end{array}$ & $\begin{array}{c}\mathrm{SP}^{*} \\
(\mathrm{~mL})\end{array}$ & \\
\hline OPC & 1,000 & 650 & 2,750 & - & - & - & 107 \\
\hline NS 12 nm & 910 & 632 & 2,750 & 90 & - & 36 & 112 \\
\hline NS $20 \mathrm{~nm}$ & 910 & 640 & 2,750 & 90 & - & 20 & 108 \\
\hline NS $40 \mathrm{~nm}$ & 910 & 644 & 2,750 & 90 & - & 12 & 110 \\
\hline SF $100 \mathrm{~nm}$ & 910 & 646 & 2,750 & - & 90 & 8 & 106 \\
\hline
\end{tabular}

${ }^{*}$ Superplasticizer.

Remark. The water in the superplasticizer (SP) was typically assumed to be $50 \%$ and taken into account by adjusting water content for each mixture proportion $[22,25,26]$.

the weight loss after the specimen was ground for 12 minutes with a rotating cutter, in accordance with ASTM C944 [29]. Three mortar specimens were determined for each tested result.

2.2.4. Water Permeability. The water permeability of control cement mortar (OPC) and cement mortar containing SF and NS was measured at the age of 28 days. Cement mortars with a diameter of $100 \mathrm{~mm}$ and thickness of $30 \mathrm{~mm}$ were used to determine the water permeability. Water with 5-bar pressure was applied to the mortar specimen for measuring the flow rate of water. Three mortar specimens were determined for each tested result. A mortar specimen and the housing cell for the water permeability test are shown in Figure 1. After a steady flow rate was obtained, the coefficient of permeability was calculated based on Darcy's law [30] as shown in

$$
K=\frac{\rho L g Q}{P A},
$$

where $K$ is the coefficient of water permeability $(\mathrm{m} / \mathrm{sec}), \rho$ is the density of water $\left(\mathrm{kg} / \mathrm{m}^{3}\right), g$ is acceleration due to gravity, $9.81\left(\mathrm{~m} / \mathrm{sec}^{2}\right), Q$ is the flow rate $\left(\mathrm{m}^{3} / \mathrm{sec}\right), L$ is the thickness of the mortar sample $(\mathrm{m}), P$ is the absolute water pressure
$\left(\mathrm{N} / \mathrm{m}^{2}\right)$, and $A$ is the cross-sectional area of the mortar sample $\left(\mathrm{m}^{2}\right)$.

2.2.5. Drying Shrinkage. The tested specimens of cement mortar for determining drying shrinkage value were prismatic, with a cross section of $25 \times 25 \mathrm{~mm}^{2}$ and a length of $285 \mathrm{~mm}$. After 24 hours of casting, the specimens were removed from the molds and then cured in water for another 48 hours. After cement mortar age of 3 days, the specimens were removed from the water and wiped with a cloth, and the initial length was measured immediately. Then, the specimens were kept in air at a temperature of $23 \pm 2^{\circ} \mathrm{C}$ and relative humidity of $50 \pm 5 \%$, in accordance with ASTM C 596 [31], and drying shrinkage was monitored for at least 3 months by using a length comparator with a precision of $2 \mu \mathrm{m}$. The first measurement was taken after 24 hours of mixing, while the rest of the measurements were taken at different ages of 3, 7, 14, 28, 60, and 90 days, respectively. Three specimens were also determined for each tested result.

2.2.6. Baenziger Block. The Baenziger block was specifically designed to generate stresses and strains at precise locations in order to allow the cement mortars to crack if they were not well formulated. The technical summary of the Baenziger 
TABLE 3: Baenziger block technical summary.

\begin{tabular}{ll}
\hline Materials & $\begin{array}{l}\text { Normal concrete } \\
\text { Cement content } 300-350 \mathrm{~kg} / \mathrm{m}^{3} \text { Portland cement type I }\end{array}$ \\
\hline Aggregate (gravel) & $0-16 \mathrm{~mm}$ \\
\hline Reinforcement & High-yield ribbed $6 \mathrm{~mm}$ diameter bars at $100 \mathrm{~mm}$ centers \\
\hline Surface finish & Sandblasted to standard EN 1766 (minimum $2 \mathrm{~mm}$ roughness) \\
\hline Baenziger block volume & Approx. $28 \mathrm{~L}$ \\
\hline Weight & Unfilled: approx. $60 \mathrm{~kg}$ \\
\hline Special requirements & Filled: approx. $81 \mathrm{~kg}$ \\
\hline
\end{tabular}

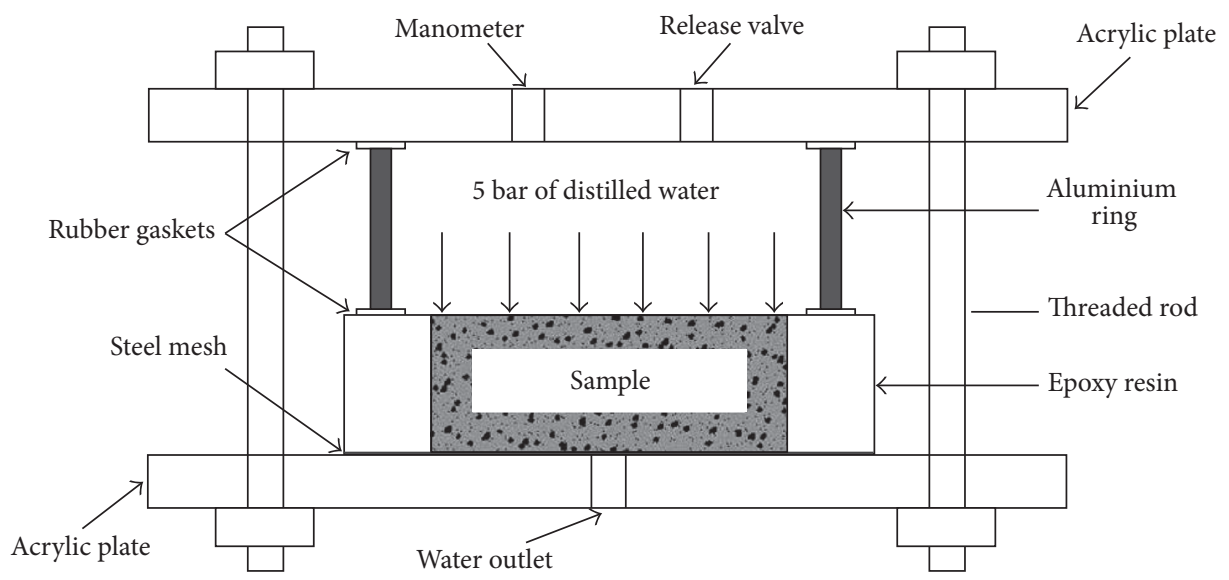

FIGURE 1: Schematic representation of the permeability housing cell [30].

block, a specially designed prefabricated test substrate originally developed by Heinz Baenziger and Alexander Bleibler [32], is given in Table 3.

The support slab dimension was $1,050 \mathrm{~mm}$ by $350 \mathrm{~mm}$, while the thickness of the cement mortar was fixed at $30 \mathrm{~mm}$ for the first $500 \mathrm{~mm}$ length and then varied from 30 to $60 \mathrm{~mm}$ for additional $650 \mathrm{~mm}$ length. Figure 2 presents a schematic view of the Baenziger block geometry [32]. This method was developed to evaluate the performance of repair materials with respect to cracking tendency and adhesion to a concrete substrate, in accordance with Schiegg and Baenziger [33]. The test was conducted simply by casting the repair material on the previously sandblasted concrete surface of the Baenziger block and subjecting it to a drying environment. Appearance of cracks was checked daily during the first week and weekly thereafter. The crack was normally observed for 3 months.

2.2.7. Adhesive Strength Test (Pull-OffMethod). The adhesion strength between overlay material of cement mortars containing SF and NS and the concrete substrate was characterized by pull-off of the cored samples taken from Baenziger block after 28 days, in accordance with ASTM C1583 [34]. According to the standard, the overlay repair cement mortars and concrete substrate were core-cut through overlay or repair material to at least $10 \mathrm{~mm}$ below the interface. A cylindrical steel disk of $50 \mathrm{~mm}$ diameter was glued to overlay or repair cement mortar using epoxy adhesive. Then, the pull-off load from the tensile loading device was applied to the tested specimen with a rate of $35 \pm 15 \mathrm{kPa} / \mathrm{sec}$ until failure occurred. The pull-off adhesive strength was calculated by dividing the tensile pull-off load at failure by the circular cut area of the tested specimen. Figure 3 shows the tensile bond strength test (pull-off method) device used for this experiment.

\section{Results and Discussion}

3.1. Abrasion Resistance. The weight losses representing the abrasion resistance of control cement mortar (OPC), cement mortar with SF, and cement mortar with various particle sizes of NS are illustrated in Figure 4 and indicated that the abrasion resistance of cement mortar with NS was remarkably improved.

Cement mortar with NS gave higher abrasion resistance than that of control cement mortar and cement mortar with SF. The reasons may come from the fact that cement mortar with NS has a less porous structure (i.e., without visible pores) and results in a denser and more compact texture [20]. Similar results were found in the works of Riahi and Nazari [35], Nazari and Riahi [36], Soleymani [37], and Li et al. [18] who studied the abrasion resistance of concrete modified with NS. These works suggested that the abrasion resistance increased with the addition of NS for all ages of cement mortar. By considering the effect of NS particle size on abrasion resistance which is the main objective of this 


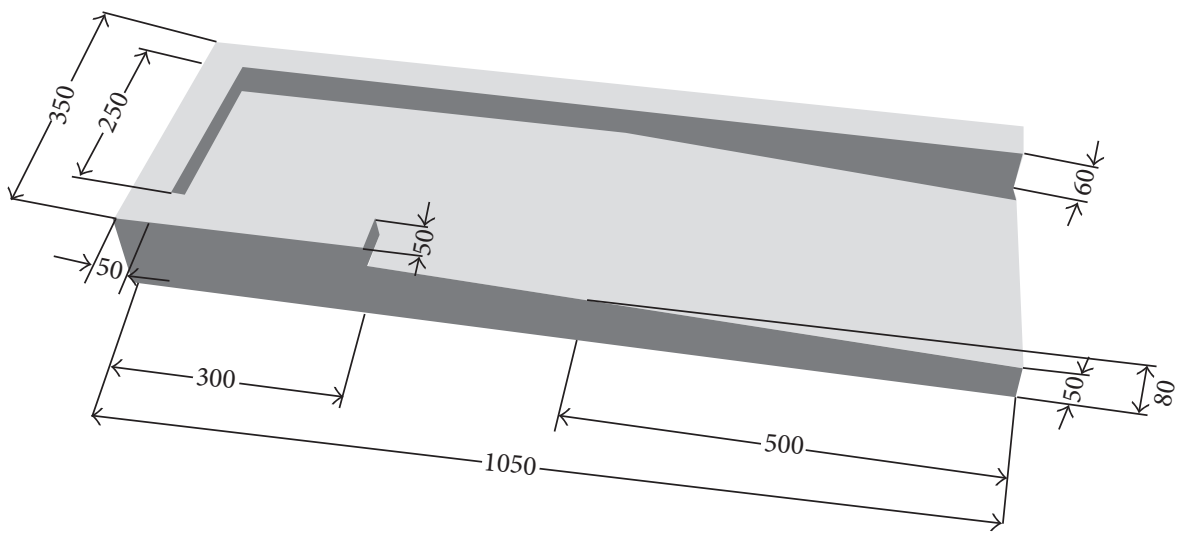

All dimensions are measured in millimeters

FIgURE 2: Dimension and preparation of Baenziger block [32].

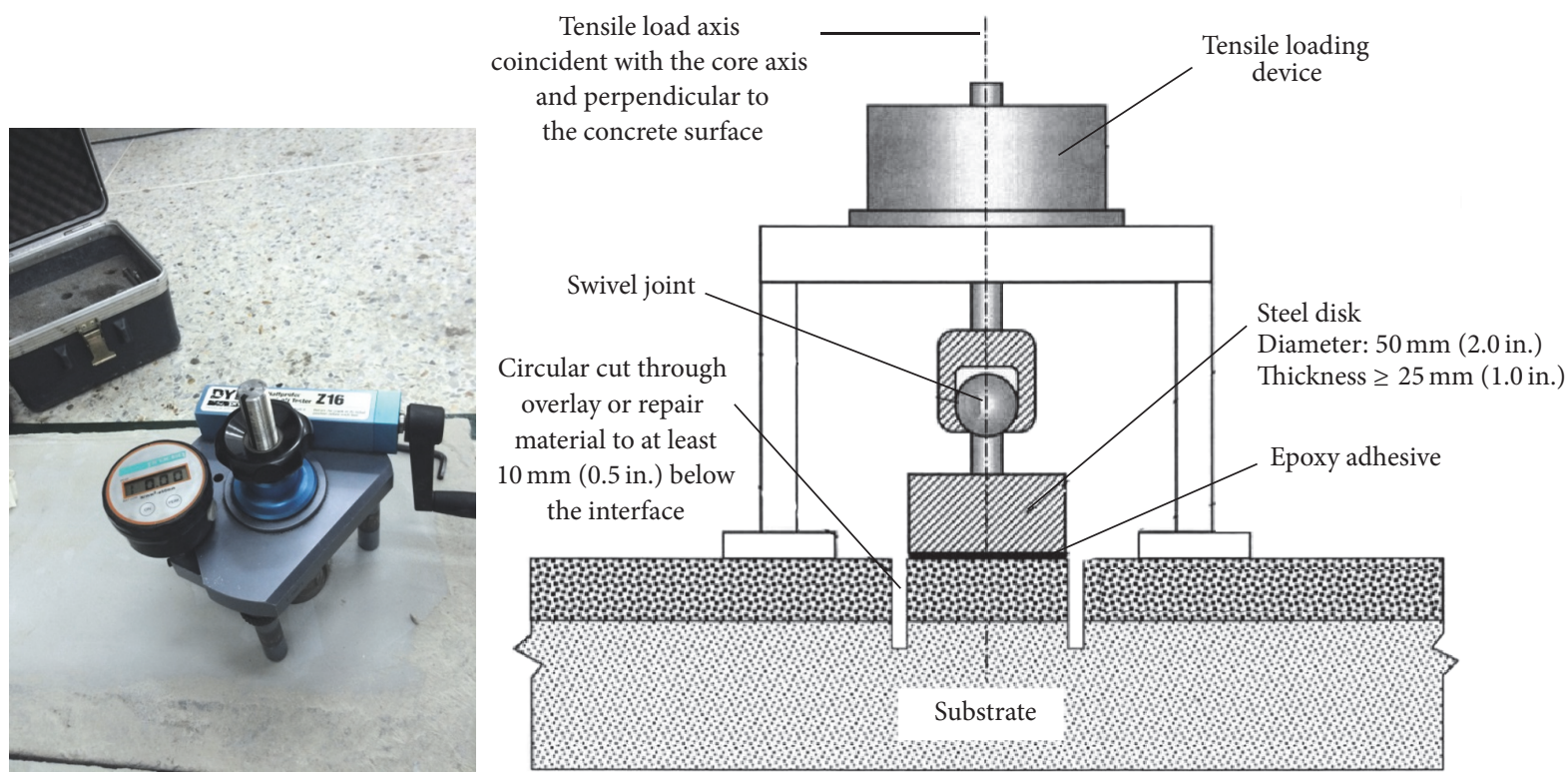

FIGURE 3: Direct tensile strength test (pull-off method) device [34].

study, the obtained results showed that the control cement mortars (OPC) gave the highest weight loss $(3.57 \mathrm{~g}$ ) while cement mortar containing NS with particle sizes of $40 \mathrm{~nm}$ gave the lowest weight loss (58\% of OPC) indicating the improvement of abrasion resistance of NS particle size of $40 \mathrm{~nm}$. By increasing NS particle sizes, the abrasion resistance of cement mortar was increased. The maximum abrasion resistance (lowest weight loss) was obtained for mortar with NS particle size of $40 \mathrm{~nm}$ and then abrasion resistance was decreased for mortar with SF $(100 \mathrm{~nm})$. Therefore, the particle size of nanosilica affected directly the abrasion resistance. Similar behavior representing the size effect of nanosilica was also found in case of epoxy/silica composite coating material [38]. This research discovered that epoxy coatings containing medium size of NS particles (53 and $79 \mathrm{~nm}$ ) had relatively higher adhesion strength, scratch resistance, and corrosion resistance than those of epoxy coating containing a very small size of NS particle $(27 \mathrm{~nm})$ and very big size of NS particle $(173 \mathrm{~nm})$.

Finally, the relationship between the abrasion resistance in terms of weight loss and the various sizes of nanoparticles is shown in Figure 5. It can be clearly seen that the abrasion resistance of cement mortar with NS particle increased with increasing nanoparticle size until NS particle size of $40 \mathrm{~nm}$ and then decreased significantly for mortar with SF $(100 \mathrm{~nm})$. This can be explained by the fact that the uniform dispersion for very small sizes of NS particle (12 and $20 \mathrm{~nm}$ ) with high specific surface area is more difficult than that of medium particle size $(40 \mathrm{~nm})$ and therefore very small particle sizes possibly result in agglomeration. The results of the microstructure by SEM as presented in the authors' previous work [22] also confirmed that cement mortar with NS $12 \mathrm{~nm}$ and $20 \mathrm{~nm}$ tended to present ineffective dispersion or agglomeration which can be observed 


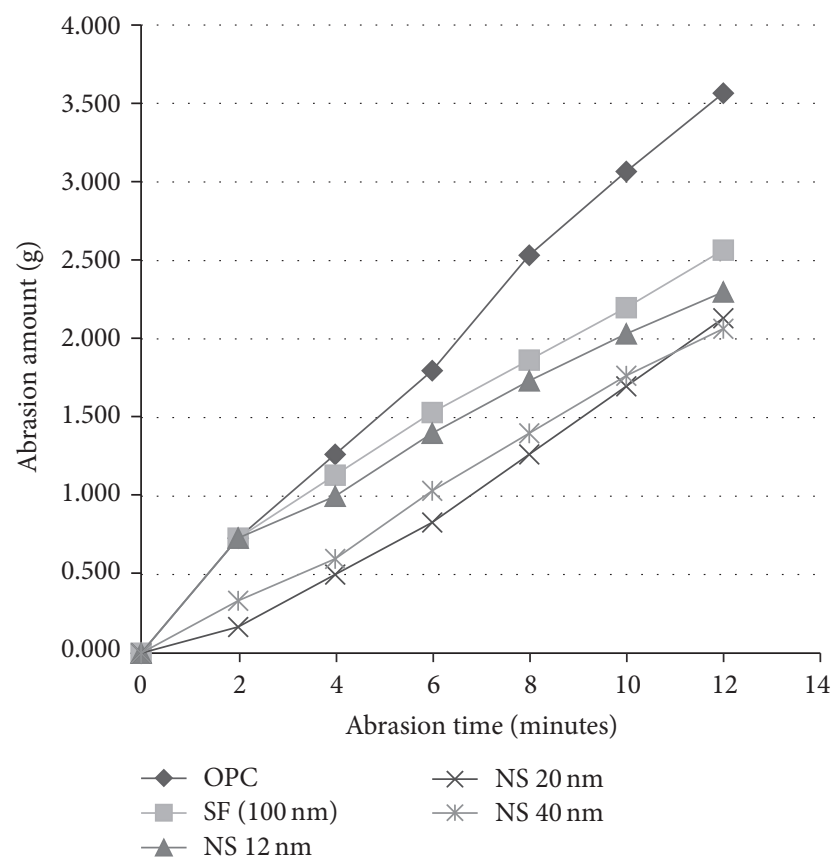

Figure 4: Abrasion resistance over time of control cement mortar, cement mortar with SF, and cement mortar with various particle sizes of NS with the replacement content of $9 \%$.

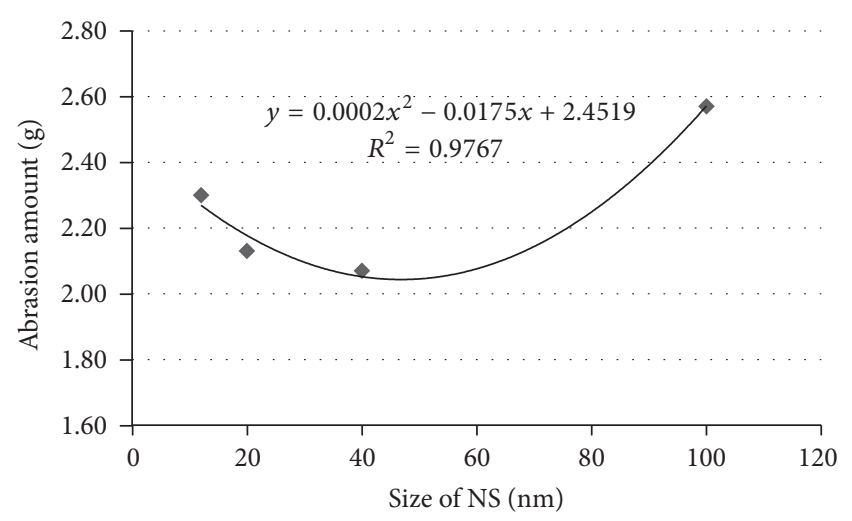

FIGURE 5: Effect of nanosilica particle size on abrasion resistance of cement mortar containing various particle sizes of NS and SF.

from the nonhomogeneous microstructure. However, the microstructure photograph of cement mortar with NS $40 \mathrm{~nm}$ was homogeneous, dense, and compact. For cement mortar with SF $(100 \mathrm{~nm})$, it has lower $\mathrm{SiO}_{2}$ content, which produces less pozzolanic activity than that of NS. Moreover, the particle size of SF is larger than that of NS, therefore giving it weaker packing ability $[18,26]$.

3.2. Water Permeability. Figure 6 shows the coefficient of water permeability of control cement mortar (OPC), cement mortar with SF, and cement mortar with various particle sizes of NS. All cement mortars with NS presented lower coefficients than those of control cement mortar and cement mortar with SF. This is because NS particle size is very small

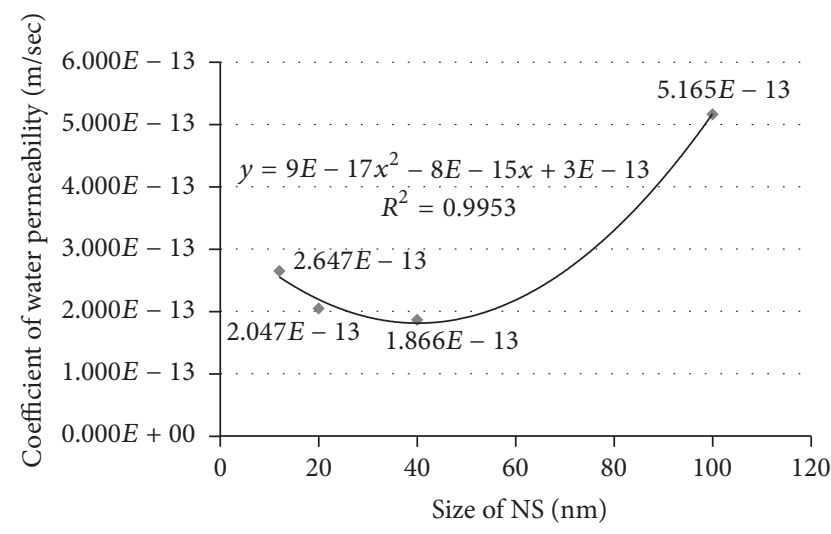

FIGURE 6: Effect of nanosilica particle size on coefficient of water permeability of cement mortar containing various particle sizes of NS and SF.

and could easily fill in the pores of cement paste and also recover the particle packing density of the cement mortar. Another reason is that NS particles possibly blocked the passages connecting capillary pores and water channels in cement paste [39]. Same behaviors concerning permeability improvements of concrete with NS were also reported by Najigivi et al. [40], Quercia et al. [41], and Esmaeili and Andalibi [42]. However, only single-sized NS particles were discussed in these researches.

In regard to the effect of NS particle size, cement mortar with NS particle size of $40 \mathrm{~nm}$ gave a lower coefficient of water permeability than those of cement mortars with NS particle sizes of 12 and $20 \mathrm{~nm}$ and cement mortar with SF $(100 \mathrm{~nm})$. In other words, the coefficient of water permeability decreases with increasing nanoparticle size up to $40 \mathrm{~nm}$ and then increases for cement mortar with SF $(100 \mathrm{~nm})$. It can be explained again that very small NS particle sizes (12 and $20 \mathrm{~nm}$ ) are not beneficial for the packing ability and possibly result in lower dispersion as mentioned previously while the medium size of nanoparticle $(40 \mathrm{~nm})$ is a suitable size which is very effective in terms of pozzolanic activity, packing ability, and uniform particle dispersion. The results of water permeability obtained from this investigation showed good correlation with our previous research [22] which found that cement mortar with medium particle size $(40 \mathrm{~nm})$ gave higher compressive strength and better microstructure than that of very small particle size (12 and $20 \mathrm{~nm}$ ). The higher the compressive strength, the lower the coefficient of water permeability typically obtained. Another previous research also suggested that agglomeration and low dispersion of very small particle size $(12 \mathrm{~nm})$ of NS affected directly the mechanical properties and microstructure [43].

3.3. Drying Shrinkage. The shrinkage behavior of control cement mortar (OPC), cement mortar with SF $(100 \mathrm{~nm})$, and cement mortar containing various particle sizes of NS (12, 20, and $40 \mathrm{~nm}$ ) is shown in Figure 7. The obtained results indicated that the cement mortars with NS $(12,20$, and $40 \mathrm{~nm})$ and SF $(100 \mathrm{~nm})$ exhibited greater shrinkage than that of the control cement mortar. This can be explained 


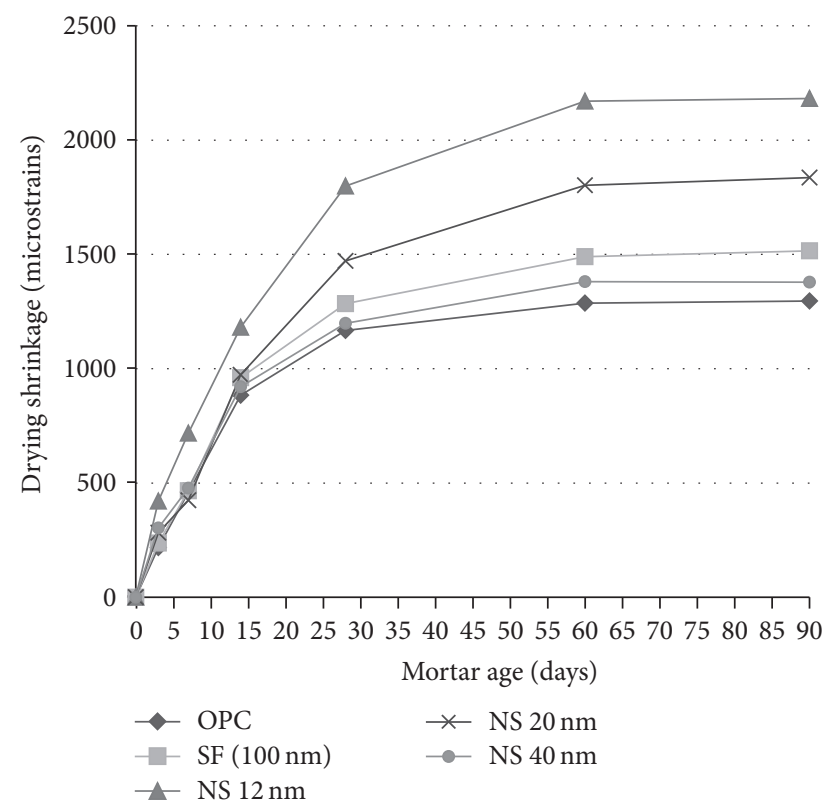

FIGURE 7: Drying shrinkage behavior of control cement mortar (OPC), cement mortar with SF, and cement mortar with various particle sizes of NS with the replacement content of $9 \%$.

by the fact that NS particles act as activators to accelerate cement hydration; therefore, a higher degree of hydration was obtained for cement mortar with NS and resulted in the increment of autogenous shrinkage and related chemical shrinkage [44]. One more work [45] related to shrinkage properties of cement mortar containing NS also suggested that cement mortar containing NS experienced higher values of drying shrinkage than cement mortar without NS. Moreover, the drying shrinkage increased with increasing nanosilica content.

In order to study the effect of particle size on drying shrinkage, it can be seen that cement mortar with NS particle size of 12 and $20 \mathrm{~nm}$ gave higher shrinkage values compared with those with NS particle size of $40 \mathrm{~nm}$ and cement mortar with SF $(100 \mathrm{~nm})$. Moreover, the cement mortar with NS particle size of $40 \mathrm{~nm}$ gave the lowest drying shrinkage. One reason is that cement mortar with very small NS particle sizes (12 and $20 \mathrm{~nm}$ ) gave low packing ability and high porosity which can be also confirmed by the previous results of water permeability. The previous work [46] also suggested that high porosity greatly influenced directly the water absorption and shrinkage cracking of cement mortar. Although the porosity on cement mortars with NS particles was not measured directly in this work, the results of microstructure obtained by SEM test presented in our previous work [22] also indicated that cement mortars containing NS particles typically gave more homogeneous, denser, and more compact textures than that of the cement mortar without NS. Another possible reason arises from the fact that very small particles of NS (12 and $20 \mathrm{~nm}$ ) have a high specific surface area. Higher surface area of NS typically consumes a high amount of water and results in higher shrinkage. Moreover, higher surface area of the cementitious material can increase the amount of heat
TABLE 4: Number of cracks in cement mortar with OPC, cement mortar with various particle sizes of NS, and cement mortar with SF at all ages.

\begin{tabular}{|c|c|c|c|c|}
\hline \multirow{2}{*}{ Samples } & \multicolumn{3}{|c|}{ Number of cracks } & \multirow{2}{*}{ Total cracks } \\
\hline & 1 day & 28 days & 90 days & \\
\hline OPC & 0 & 0 & 1 & 1 \\
\hline NS $12 \mathrm{~nm}$ & 19 & 11 & 6 & 36 \\
\hline NS $20 \mathrm{~nm}$ & 0 & 19 & 8 & 27 \\
\hline NS $40 \mathrm{~nm}$ & 0 & 0 & 2 & 2 \\
\hline $\mathrm{SF} 100 \mathrm{~nm}$ & 2 & 1 & 2 & 5 \\
\hline
\end{tabular}

evolved during the setting and hardening of the cement and can directly affect the drying shrinkage of cement mortar [47].

3.4. Baenziger Block. This research presents the cracking behavior after allowing the cement mortar to harden for 1, 28, and 90 days. The results obtained from Baenziger block test of control cement mortar without NS (OPC), cement mortar with NS particle sizes of 12, 20, and $40 \mathrm{~nm}$, and cement mortar with SF $(100 \mathrm{~nm})$ at age of 1 day are presented in Figure 8. These results clearly show that control cement mortar without NS (OPC) and cement mortar with NS particle sizes of 20 and $40 \mathrm{~nm}$ produced no cracking, while cement mortar with SF resulted in some small cracks near the edges and corners of the block. Multiple fine cracks, widely distributed along the length of the specimen, occurred in cement mortar with NS particle size of $12 \mathrm{~nm}$. In the case of cement mortar at the age of 28 days (Figure 9), no cracks appeared for control cement mortar and cement mortar containing NS particle size of $40 \mathrm{~nm}$, while cement mortar with NS particle size of $20 \mathrm{~nm}$ gave multiple fine cracks. The crack patterns of cement mortar with NS particle size of $20 \mathrm{~nm}$ were almost the same as for cement mortar with NS particle size of $12 \mathrm{~nm}$. Figure 10 presents the crack pattern of cement mortars at the age of 90 days. These results indicated that control cement mortar and cement mortar with NS particle size of $40 \mathrm{~nm}$ generated only cracking near the edges and corners of the block (about 1-2 cracks), while cement mortar with SF produced higher crack number (around 5 cracks). However, cement mortar with NS particle sizes of 12 and $20 \mathrm{~nm}$ generated continuous cracking (about 36 and 27 cracks, resp.), as shown in Table 4.

In terms of the number of cracks, cement mortar containing NS particle sizes containing 12 and $20 \mathrm{~nm}$ generated a higher number of cracks than that of cement mortar containing $40 \mathrm{~nm}$. This can be explained by the fact that very small particles of NS result in a higher hydration temperature. Moreover, particles with very small size typically gave higher specific surface area which can result in a higher interface area and high degree of cracking [48]. These cracking behaviors from the Baenziger block test clearly supported the results of the drying shrinkage described previously. As observed in Figures 8 and 9, the cracking of cement mortar with NS particle sizes of 12 and $20 \mathrm{~nm}$ started from cement mortars at the age of 1 and 28 days, respectively, which is consistent with the drying shrinkage behavior, as shown in Figure 7. 


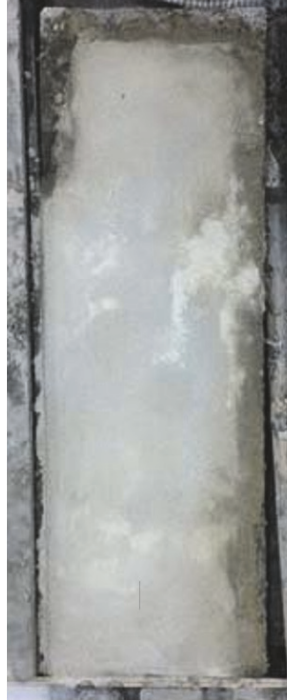

OPC

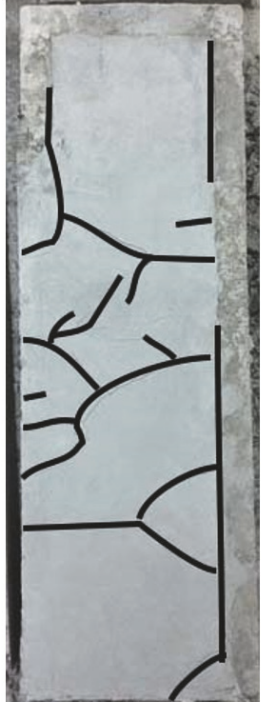

NS $12 \mathrm{~nm}$

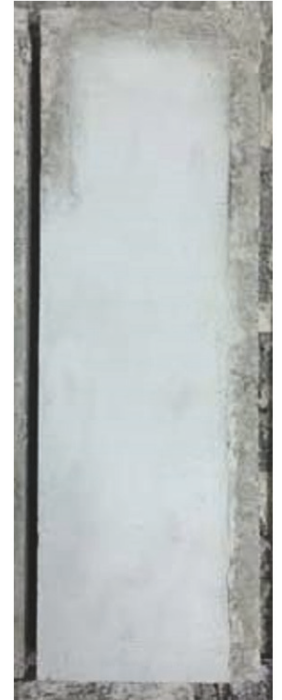

NS $20 \mathrm{~nm}$

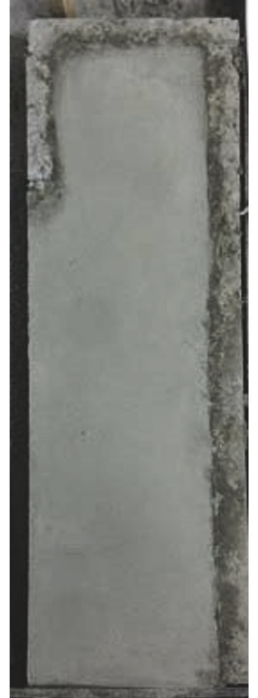

NS $40 \mathrm{~nm}$

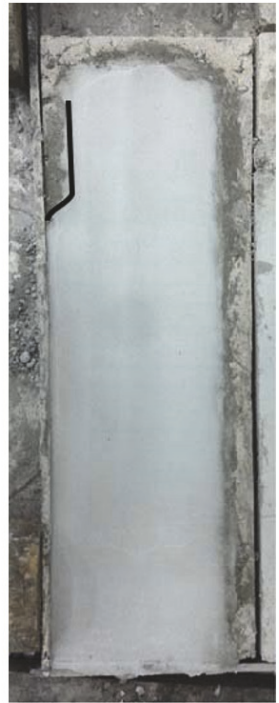

$\mathrm{SF}$

FIGURE 8: Cracking behavior of control cement mortar (OPC), cement mortar with SF, and cement mortar with various particle sizes of NS at mortar age of 1 day in Baenziger blocks.

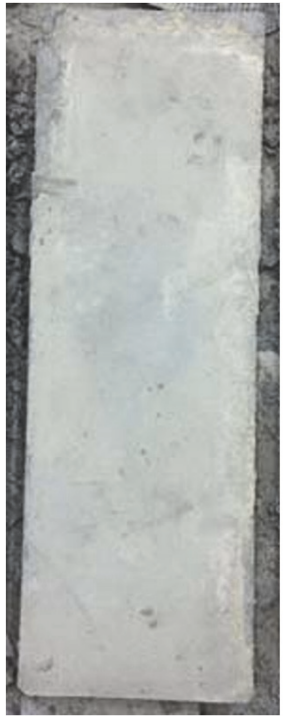

OPC

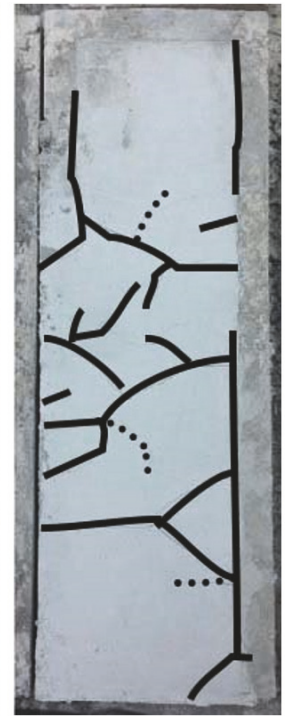

NS $12 \mathrm{~nm}$

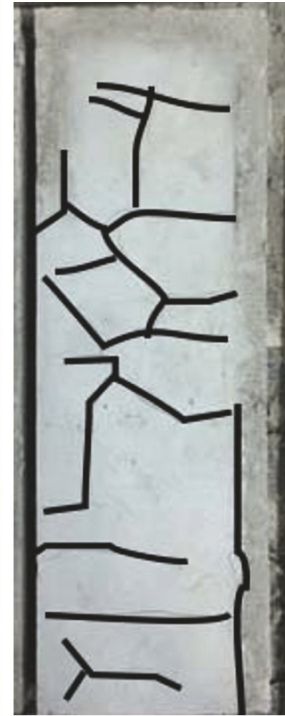

NS $20 \mathrm{~nm}$

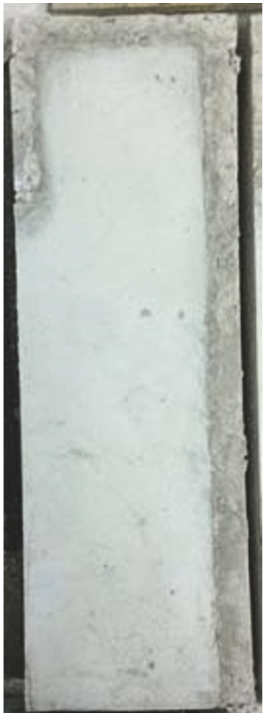

NS $40 \mathrm{~nm}$

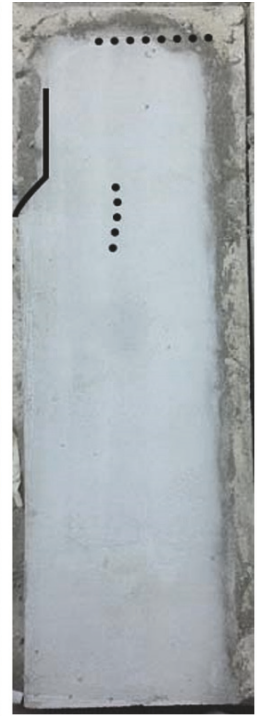

SF

- Existing cracks

..... Additional cracks from 1 through 28 days

FIGURE 9: Cracking behavior of control cement mortar (OPC), cement mortar with SF, and cement mortar with various particle sizes of NS at mortar age of 28 days in Baenziger blocks.

3.5. Adhesive Strength (Pull-Off Method). Figure 11 presents the adhesive strength obtained from the pull-off method for control cement mortar without NS (OPC), cement mortar with various particle sizes of NS, and cement mortar with SF.

By considering the adhesive strength obtained from the pull-off method of cored samples taken from the Baenziger block, the highest value $(2.57 \mathrm{MPa})$ was obtained for OPC while the lowest value $(0.36 \mathrm{MPa})$ was obtained for cement mortar with NS particle size of $12 \mathrm{~nm}$. An increase in adhesive strength was also observed with increasing of NS particle sizes: for example, NS particle sizes of 12, 20, and $40 \mathrm{~nm}$ had values of $0.36,0.61$, and $2.27 \mathrm{MPa}$, respectively. For all cases, the failures occurred in the transition zone [49] between the repair cement mortar and the substrate concrete. 


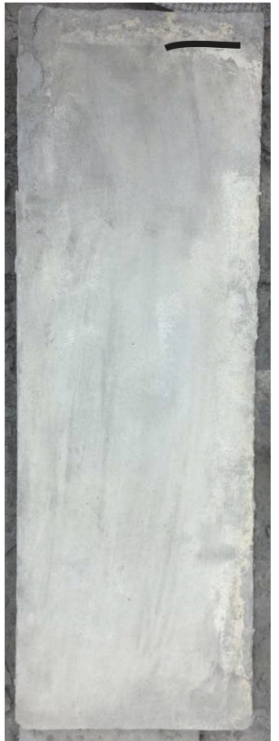

OPC

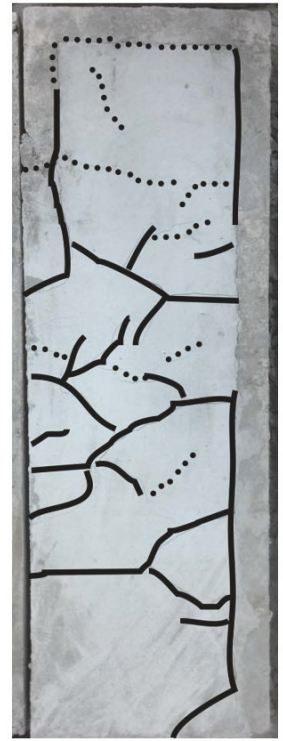

NS $12 \mathrm{~nm}$

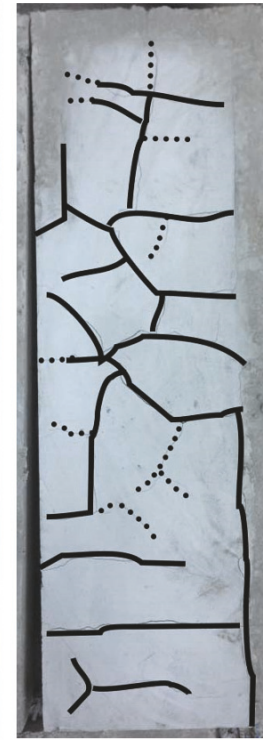

NS $20 \mathrm{~nm}$

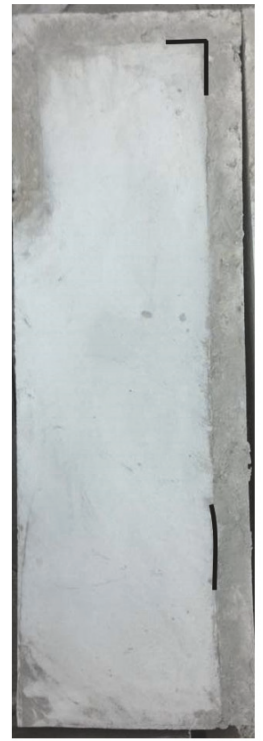

NS $40 \mathrm{~nm}$

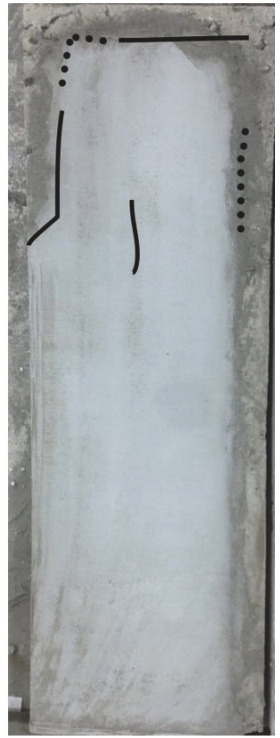

SF

.... Additional cracks from 28 through 90 days

FIGURE 10: Cracking behavior of control cement mortar (OPC), cement mortar with SF, and cement mortar with various particle sizes of NS at mortar age of 90 days in Baenziger blocks.

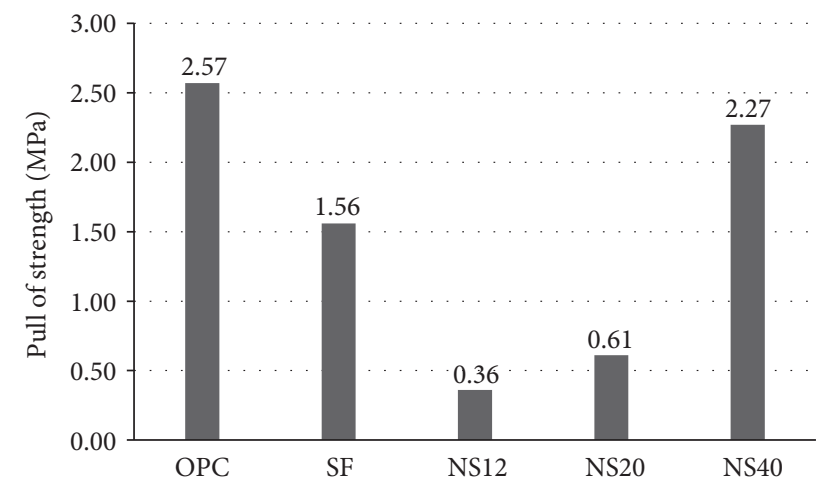

FIGURE 11: Pull-off strength of control cement mortar (OPC), cement mortar with SF, and cement mortar with various particle sizes of NS.

However, in the control cement mortar and cement mortar with NS particle size of $40 \mathrm{~nm}$, the failures occurred in the substrate concrete (underlying the Baenziger block). In this situation, the repair cement mortar overlay can be considered successful, as the strength of the bonding surface and the repair cement mortar overlay is greater than the strength of the underlying Baenziger block concrete. For cement mortar with NS particle sizes of 12 and $20 \mathrm{~nm}$ and cement mortar with SF, the failures occurred in the repair cement mortar overlay (above the bonding surface) which indicates that the bonding surface and substrate concrete (Baenziger block) have higher strength than the repair cement mortar overlay. Therefore, these repair materials are not suitable for repair work. These results also indicate that the adhesive strength of the repair cement mortar from Baenziger block decreased with increasing crack number of the sample. As mentioned previously, in cement mortars with smaller NS particle sizes (12 and $20 \mathrm{~nm}$ ) which resulted in higher drying shrinkage and crack number, their adhesive strength reduced significantly. The obtained results were also supported by the previous research related to the evaluation of crack opening performance of a repair material [14]. This work suggested that insufficient bond properties induced delamination at the interface between the repair material and the substrate, which gives the potentially misleading result of a more widely distributed cracked area. Moreover, the tensile strength (pulloff strength) can be related to the intensity of cracking (number of cracks) observed on experimental repairs [50]. A previous study [51] on the durability of concrete repair also reported that failure of a concrete repair is more likely to occur either due to incompatibility between the repair material and concrete or due to high shrinkage levels. Both of these factors can lead to cracking and debonding of the repair material.

\section{Conclusions}

Based on the results of experiments performed on repair material made from cement mortar containing nanosilica (NS), the following conclusions can be drawn:

(1) The abrasion resistance and water permeability of cement mortar were improved by the addition of all particle sizes of NS $(12,20$, and $40 \mathrm{~nm})$ and were comparatively better than those of the control cement mortar and cement mortar with SF. 
(2) Nanosilica particle size affected significantly the water permeability and abrasion resistance. By increasing the nanoparticle size (ranging between 12, 20, and $40 \mathrm{~nm}$ ), the water permeability and abrasion resistance of cement mortar containing NS increased. The maximum result was obtained for cement mortar with $40 \mathrm{~nm}$ and then decreased significantly for cement mortar with SF $(100 \mathrm{~nm})$.

(3) The particle sizes of NS also affected the drying shrinkage of cement mortar. Cement mortars containing a very small particle size of NS (12 and $20 \mathrm{~nm}$ ) experienced higher drying shrinkage and crack number in comparison with control cement mortar and cement mortar containing $40 \mathrm{~nm}$ of NS.

(4) The adhesive strength of cement mortar with NS decreased for cement mortar containing very small NS particle sizes (12 and $20 \mathrm{~nm}$ ). This was related to the intensity of cracking (number of cracks) observed on the Baenziger block test.

(5) The particle size of NS affects not only durability properties (abrasion and water permeability) but also the repair work properties (drying shrinkage, cracks, and adhesive strength) of cement mortar. Nanosilica particle size of $40 \mathrm{~nm}$ is the optimum size.

\section{Conflicts of Interest}

The authors declare that they have no conflicts of interest.

\section{Acknowledgments}

The authors gratefully acknowledge the Institutional Research Capability Development Grant from Thailand Research Fund (TRF) and King Mongkut's University of Technology Thonburi (KMUTT). The authors would also like to thank Mr. Udomsak Boonkrai and Mr. Purithat Suwanachote for their contributions and generous cooperation.

\section{References}

[1] P. S. Mangat and M. C. Limbachiya, "Repair material properties for effective structural application," Cement and Concrete Research, vol. 27, no. 4, pp. 601-617, 1997.

[2] N. Emberson and G. Mays G, "Significance of property mismatch in the patch repair of structural concrete, part I: properties of repair systems," Magazine of Concrete Research, vol. 42, no. 152, pp. 147-160, 1990.

[3] P. Emmons and B. Emmons, "Surface repair section 6: bonding repair materials to existing concrete," in Book of Concrete Repair and Maintenances Illustrated, John Wiley \& Sons, Chichester, UK, 1994.

[4] M. Berra, F. Carassiti, T. Mangialardi, A. E. Paolini, and M. Sebastiani, "Leaching behaviour of cement pastes containing nanosilica," Advances in Cement Research, vol. 25, no. 6, pp. 352361, 2013.

[5] M. Morency, A. Vaysburd, K. Vonfay, and B. Bissonnette, "Development of a test method to evaluate cracking tendency of repair materials," Phase I Report Research Report 2004-1, CRC Press, New York, NY, USA, 2005.

[6] G. Li, H. Xie, and G. Xiong, "Transition zone studies of newto-old concrete with different binders," Cement and Concrete Composites, vol. 23, no. 4-5, pp. 381-387, 2001.

[7] E. N. B. S. Júlio, F. A. B. Branco, and V. D. Silva, "Concreteto-concrete bond strength. Influence of the roughness of the substrate surface," Construction and Building Materials, vol. 18, no. 9, pp. 675-681, 2004.

[8] M. Sierra and H. H. Jonkers, "Bio-based mortar for concrete repair," in Proceedings of the 14th International Conference Structural Faults and Repair, London, UK, 2004.

[9] K. Fukuzawa, M. Mitsui, and T. Numao, "Surface roughness indexes for evaluation of bond strengths between CRFP sheet and concrete," in Proceedings of the 10th International Conference Congress on Polymers in Concrete, Honolulu, Hawaii, USA, 2001.

[10] R. Mackowski, "The effect of concrete surface treatment on the quality of the concrete structure repair," in Proceedings of the 10th Conference on Corrosion and Durability of Structures, Zakopane, Poland, May 2000.

[11] L. P. Singh, A. Goel, S. K. Bhattachharyya, S. Ahalawat, U. Sharma, and G. Mishra, "Effect of nanosilica on chloride permeability in cement mortar," Advances in Cement Research, vol. 27, no. 7, pp. 399-408, 2015.

[12] A. Kamal, M. Kunieda, N. Ueda, and H. Nakamura, "Evaluation of crack opening performance of a repair material with strain hardening behavior," Cement and Concrete Composites, vol. 30, no. 10 , pp. 863-871, 2008.

[13] S. Li and T. Xu, "Effect of nanosilica on the fresh properties of cement-based grouting material in the portlandsulphoaluminate composite system," Advances in Materials Science and Engineering, vol. 2016, Article ID 2707465, 10 pages, 2016.

[14] K. Sobolev and M. Gutirrez, "How nanotechnology can change the concrete world," American Ceramic Society, vol. 84, no. 10, pp. 14-18, 2005.

[15] F. Sanchez and K. Sobolev, "Nanotechnology in concrete-a review," Construction and Building Materials, vol. 24, no. 11, pp. 2060-2071, 2010.

[16] F. T. Isfahani, E. Redaelli, F. Lollini, W. Li, and L. Bertolini, "Effects of nanosilica on compressive strength and durability properties of concrete with different water to binder ratios," Advances in Materials Science and Engineering, vol. 2016, Article ID 8453567, 16 pages, 2016.

[17] Y. Qing, Z. Zenan, K. Deyu, and C. Rongshen, "Influence of nano- $\mathrm{SiO}_{2}$ addition on properties of hardened cement paste as compared with silica fume," Construction and Building Materials, vol. 21, no. 3, pp. 539-545, 2007.

[18] H. Li, M.-H. Zhang, and J.-P. Ou, "Abrasion resistance of concrete containing nano-particles for pavement," Wear, vol. 260, no. 11-12, pp. 1262-1266, 2006.

[19] J.-Y. Shih, T.-P. Chang, and T.-C. Hsiao, "Effect of nanosilica on characterization of Portland cement composite," Materials Science and Engineering A, vol. 424, no. 1-2, pp. 266-274, 2006.

[20] T. Ji, "Preliminary study on the water permeability and microstructure of concrete incorporating nano- $\mathrm{SiO}_{2}$," Cement and Concrete Research, vol. 35, no. 10, pp. 1943-1947, 2005.

[21] M.-H. Zhang and H. Li, "Pore structure and chloride permeability of concrete containing nano-particles for pavement," Construction and Building Materials, vol. 25, no. 2, pp. 608-616, 2011. 
[22] S. Haruehansapong, T. Pulngern, and S. Chucheepsakul, "Effect of the particle size of nanosilica on the compressive strength and the optimum replacement content of cement mortar containing Nano-SiO ${ }_{2}$," Construction and Building Materials, vol. 50, pp. 471-477, 2014.

[23] E. Horszczaruk, E. Mijowska, K. Cendrowski, S. Mijowska, and P. Sikora, "The influence of nanosilica with different morphology on the mechanical properties of cement mortars," Cement, Wapno, Beton, no. 1, pp. 24-32, 2013.

[24] H. Li, H.-G. Xiao, J. Yuan, and J. Ou, "Microstructure of cement mortar with nano-particles," Composites Part B: Engineering, vol. 35, no. 2, pp. 185-189, 2004.

[25] J. M. Fernández, A. Duran, I. Navarro-Blasco, J. Lanas, R. Sirera, and J. I. Alvarez, "Influence of nanosilica and a polycarboxylate ether superplasticizer on the performance of lime mortars," Cement and Concrete Research, vol. 43, no. 1, pp. 12-24, 2013.

[26] L. Senff, J. A. Labrincha, V. M. Ferreira, D. Hotza, and W. L. Repette, "Effect of nano-silica on rheology and fresh properties of cement pastes and mortars," Construction and Building Materials, vol. 23, no. 7, pp. 2487-2491, 2009.

[27] ASTM Standards ASTM C1437, Standard Test Method for Flow of Hydraulic Cement Mortar, American Society for Testing and Materials Annual book of ASTM Standards, West Conshohocken, Pa, USA, 2007.

[28] ASTM Standards, "Standard specification for standard sand," in American Society for Testing and Materials Annual Book of ASTM Standards, ASTM C778, ASTM, West Conshohocken, $\mathrm{Pa}, \mathrm{USA}, 2000$.

[29] ASTM Standards ASTM C 944, Standard Test Method for Abrasion Resistance of Concrete or Mortar Surfaces by the RotatingCutter Method, American Society for Testing and Materials. Annual book of ASTM Standards, West Conshohocken, Pa, USA, 2013.

[30] R. P. Khatri and V. Sirivivatnanon, "Methods for the determination of water permeability of concrete," ACI Materials Journal, vol. 94, no. 3, pp. 257-261, 1997.

[31] ASTM Standards, "Standard test method for drying shrinkage of mortar containing hydraulic cement," in American Society for Testing and Materials Annual Book of ASTM Standards, ASTM C 596, ASTM, West Conshohocken, Pa, USA, 2013.

[32] T. Gillespie T, "New method to predict performance of concrete repair materials in the field," in Proceedings of the ICRI Spring Convention, Bali, Indonesia, 1999.

[33] A. Schiegg and H. Baenziger, "Efficient testing of fibers with the Baenziger block," in Proceedings of the Conference: Concrete Repair, Rehabilitation and Retrofitting, Cape Town, South Africa, 2006.

[34] ASTM Standards, "Standard test method for tensile strength of concrete surfaces and the bond strength or tensile strength of concrete repair and overlay materials by direct tension (pulloff method)," in American Society for Testing and Materials Annual Book of ASTM Standards, ASTM C1583, ASTM, West Conshohocken, Pa, USA, 2004.

[35] S. Riahi and A. Nazari, "Compressive strength and abrasion resistance of concrete containing $\mathrm{SiO}_{2}$ and $\mathrm{CuO}$ nanoparticles in different curing media," Science China Technological Sciences, vol. 54, no. 9, pp. 2349-2357, 2011.

[36] A. Nazari and S. Riahi, "Abrasion resistance of concrete containing $\mathrm{SiO}_{2}$ and $\mathrm{Al}_{2} \mathrm{O}_{3}$ nanoparticles in different curing media," Energy and Buildings, vol. 43, no. 10, pp. 2939-2946, 2011.
[37] F. Soleymani, "Abrasion resistance of concrete containing $\mathrm{SiO}_{2}$ nanoparticles in different curing Media," American Journal of Science, vol. 8, no. 8, pp. 171-178, 2012.

[38] J. Yuan, S. Zhou, G. Gu, and L. Wu, "Effect of the particle size of nanosilica on the performance of epoxy/silica composite coatings," Journal of Materials Science, vol. 40, no. 15, pp. 39273932, 2005.

[39] Y. Benachour, C. A. Davy, F. Skoczylas, and H. Houari, "Effect of a high calcite filler addition upon microstructural, mechanical, shrinkage and transport properties of a mortar," Cement and Concrete Research, vol. 38, no. 6, pp. 727-736, 2008.

[40] A. Najigivi, S. Rashid, F. Aziz, A. Nora, M. Sakkeh, and M. Amran, "Water absorption control of ternary blended concrete with nanosilica presence of rice husk ash," Materials and Structure, vol. 45, no. 7, pp. 1007-1017, 2012.

[41] G. Quercia, P. Spiesz, G. Husken, and J. Brouwers, "Effects of amorphous nano-silica addition on mechanical and durability performance of SCC mixtures," in Proceeding of the International Congress on Durability of Concrete, Trondheim, Norway, 2012.

[42] J. Esmaeili and K. Andalibi, "Investigation of the effects of nanosilica on the properties of concrete in comparison with microsilica," International Journal Nano Dimension, vol. 3, no. 4, pp. 321-328, 2013.

[43] M. Arefi, M. Javaheri, E. Mollaahmadi, H. Zare, B. Nejand, and M. Eskandari M, "Silica nano particle size on mechanical properties and microstructure of cement mortar," American Journal of Science, vol. 7, no. 10, pp. 231-238, 2011.

[44] A. A. Melo Neto, M. A. Cincotto, and W. Repette, "Drying and autogenous shrinkage of pastes and mortars with activated slag cement," Cement and Concrete Research, vol. 38, no. 4, pp. 565574, 2008.

[45] A. Sadrmomtazi, A. Fasihi, F. Balalaei, and A. Haghi A, "Investigation of mechanical and physical properties of mortar containing silica fume and nanosilica," in Proceedings of the $3 \mathrm{rd}$ International Conference on Concrete and Development, Tehran, Iran, 2009.

[46] D. Wilk, L. Bratasz, and R. Kozlowski, "Reducing shrinkage crack in Roman cement renders," in Proceedings of the 2nd Conference on Historic Mortars (HMC '10) and RILEM TC 203RHM Final Workshop, Prague, Czech Republic, 2010.

[47] G. C. Isaia, A. L. G. Gastaldini, and R. Moraes, "Physical and pozzolanic action of mineral additions on the mechanical strength of high-performance concrete," Cement and Concrete Composites, vol. 25, no. 1, pp. 69-76, 2003.

[48] H. A. Al-Turaif, "Effect of nano $\mathrm{TiO}_{2}$ particle size on mechanical properties of cured epoxy resin," Progress in Organic Coatings, vol. 69, no. 3, pp. 241-246, 2010.

[49] P. Emmons and A. Vaysburd, "Factor affecting durability of concrete repair," in Proceedings of the 5th International Conference on Structural Faults and Repair, Edinburgh, UK, 1993.

[50] M. Maxim, Cracking Sensitivity of Cementitious Repair Materials: Assessments and Development of Test Methods, Université Laval, Quebec, Canada, 2013.

[51] M. H. Decter, "Durable concrete repair-importance of compatibility and low shrinkage," Construction and Building Materials, vol. 11, no. 5-6, pp. 267-273, 1997. 

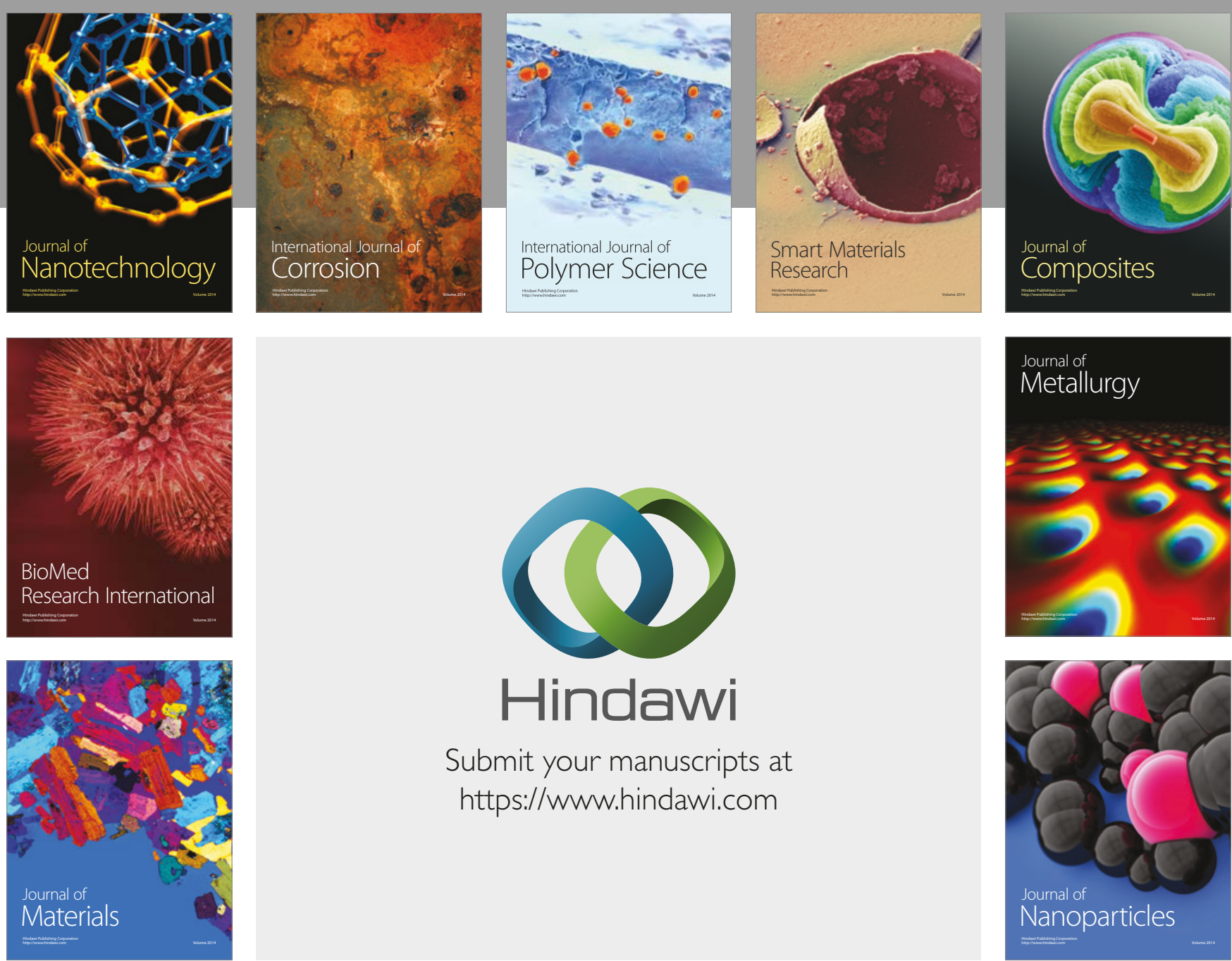

\section{Hindawi}

Submit your manuscripts at

https://www.hindawi.com
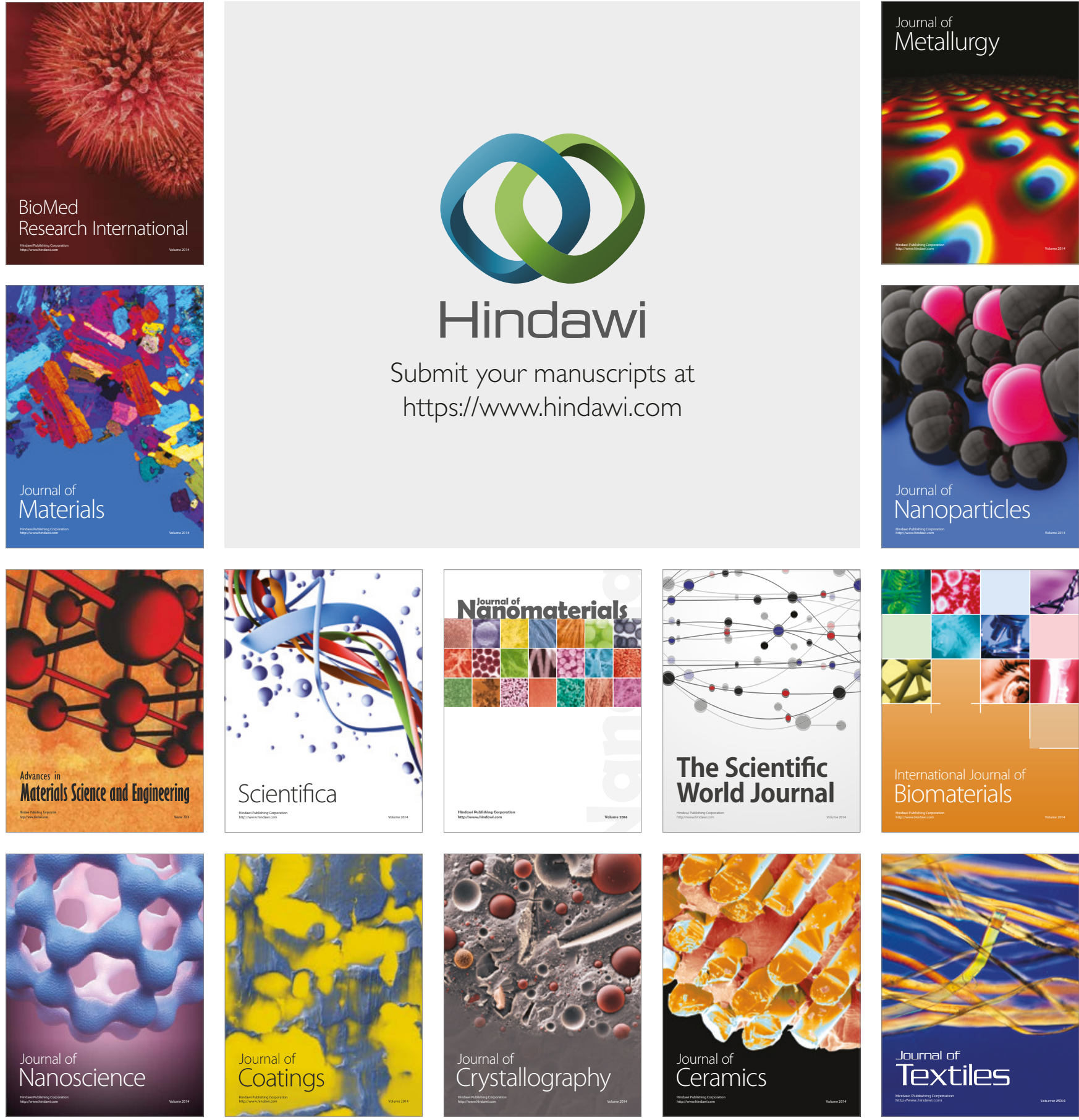

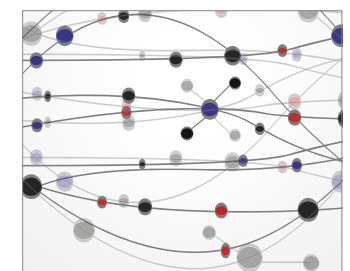

The Scientific World Journal
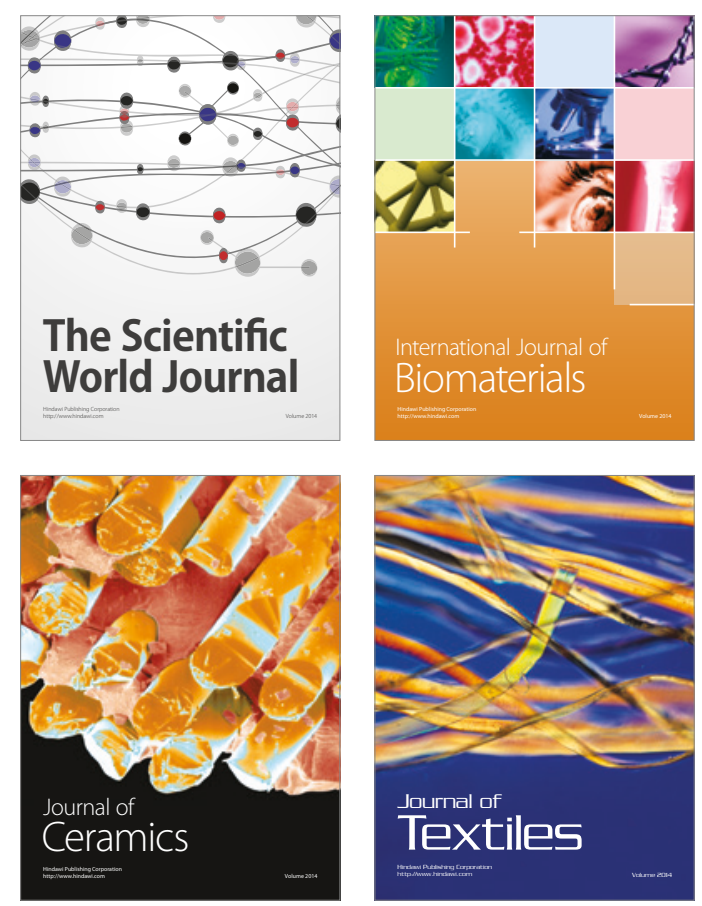